\title{
Efficiency of Alfalfa Hay Mowing Machines under the Dryland Conditions
}

\author{
Rade STANISAVLJEVIĆ, Aleksandar VUKOVIĆ, Dragan V. PETROVIĆ, Rade L. RADOJEVIĆ, Saša BARAĆ, \\ Zoran MILEUSNIĆ, Vjekoslav TADIĆ ${ }^{*}$
}

\begin{abstract}
This paper presents the tests results of three types of hay mowing machines (later in text: mowers), namely a self-propelled oscillatory mower-conditioner and two tractor-mounted mowers with oscillatory and rotary blades, used to mow alfalfa grown under dry land conditions in the region of central Serbia during three seasons in 2014, 2015 and 2016. Although characterized by older design, they are still commonly used at smaller and medium size farms in this region. Therefore, their optimal exploitation parameters are still of large importance for hay quality and production efficiency and sustainability. The exploitation parameters of all three mowers generally increased linearly with higher speeds, having high $R^{2}$ values (over 0,8 ), with rare exceptions. The regression coefficients $b$ clearly showed that the self-propelled mower-conditioner achieved maximum increase in production performance $(b=0,3606)$, compared with the oscillatory $(b=0,1158)$ and rotary mowers $(b=0,1414)$. Mower design had a significant $(p \leq 0,001)$ effect on cutting and chopping losses, production performance, and specific fuel consumption $(p \leq 0,05)$. The tests confirmed the superiority of the self-propelled mower over the two mowers aggregated with tractors.
\end{abstract}

Keywords: alfalfa; harvest; hay cutting; hay mowing machines; working performance

\section{INTRODUCTION}

Contemporary livestock forage production is an important sector of agriculture [1]. Highly intensive development of sophisticated grassland husbandry systems, based on legume growing, can be achieved by a more intensive use of legumes, which can make them a substantially important ruminant crop in the future [2]. Currently, the world production of alfalfa covers $3310^{6}$ hectares of arable land. In Serbia, this crop is grown at 103 $366 \mathrm{ha}$, at an average hay yield of $5,0 \mathrm{t} \cdot \mathrm{ha}^{-1}$ [3]. It represents a suitable fresh crop source for the preparation of hay, haylage, silage, etc. Bearing in mind this practice, this paper focuses on the analysis of hay mowing efficiency of alfalfa under dryland conditions.

Mowing height represents an important parameter that can strongly influence harvested yield and forage nutritive quality [4]. Belesky and Fedders [5] found that alfalfa mowed at $10 \mathrm{~cm}$ above the ground surface decreased the yield for up to $38 \%$ with respect to the yield collected from alfalfa crop mowed at $5 \mathrm{~cm}$. Their conclusion was confirmed by [6] who also noted that alfalfa mowing at higher heights increases further weed growth and competition for growing space, sunlight, water, minerals, fertilizers if applied, etc. in subsequent alfalfa growths. The final consequence of this competition is manifested through a more rapid reduction in alfalfa plant size with respect to low height mowing. However, according to the same authors, in addition to higher yield, low cutting height provides lower quality feed.

Therefore, alfalfa mowing height should be carefully chosen to meet the current market and environmental conditions. However, there are many other parameters influencing alfalfa yield and quality, including cutting schedule. Compared to the moderate cutting schedules, 7 or 8 cuts applied in the flatlands, or a standard 3 or 4 cuts used in the intermountain regions, a more profitable schedule is strongly related to market conditions. Literally, when crop prices are low, the yield is favoured, but when market prices are high, the quality becomes the focal point as well. Optimally, farmer mowing schedule should be adapted to meet the current market conditions [7].
Following Milić et al. [8], the three-, four- and five-cut production systems in dryland conditions, and the five-cut system for irrigated systems, are most obviously used in Serbia. If the three-cut system is applied, mowing is performed in the bud phase of alfalfa growth within the interval of about 60 days, generally between May and the end of September or later. This type of growing is extensive, using the forage potential only partially, resulting in lower quality but prolongs lifetime of the crops. Mowers should satisfy requirements of universality of application, the quality and accuracy of stem cutting with the lowest possible losses of green mass, high production output and fuel economy. Mowing operation is very important for obtaining alfalfa fodder of appropriate quality and should be performed within the optimal period to produce a high-quality forage [9]. According to [10], this interval lasts only 35 days. Hosseini and Shamsi [11], reported that optimal energy consumption and performance are of substantial importance in agricultural technology. Mowing operation consumes a substantial amount of energy and influences the forage quality, demanding harmonization of mowers design, working parameters, crop selection, etc. Along the same lines [12], recommended mowing height ranging between 3 and 4 inches $(7,6 \mathrm{~cm}$ and $10,2 \mathrm{~cm})$ and the manipulation of mowed alfalfa until it reaches $50 \%$ humidity using rotary spreaders. The treatment of the alfalfa mass having a lower percentage of moisture may result in substantial leaf mass losses. Wiersma and Wiederholt [13] noted that alfalfa should be mowed to the optimal height of 2 inches $(5,1$ $\mathrm{cm})$, which may vary between 1 and 4 inches $(2,5 \mathrm{~cm}$ and $10,2 \mathrm{~cm}$ ) depending on the specified sequence of alfalfa mowing.

All modern mowers are based on two basic types of cutting mechanisms: cutter bar (oscillatory) and rotary (disk or drum). Rotary mowers generally demand more power and fuel for operation [14] and their price is higher for a specified cut width, but their mowing capacity is higher, equalling the total mowing cost for both major types of grassland mowers [15]. According to [14], fuel and power requirements were significantly higher for the rotary drum mower. 
Based on tests of a rotary mower with drums, [16] reported that the losses due to cutting height reached $2,65 \%$, while the chopping losses decreased with higher working speeds, from $1,06 \%$ to $0,82 \%$. During comprehensive testing of an oscillatory mower with a conventional cutting apparatus and a two-drum rotary mower, [17] found that the average cutting height of the stems amounted to $6,32 \mathrm{~cm}$ when the oscillatory mower was applied and $9,53 \mathrm{~cm}$ in the case of the rotary mower. The average total operating losses caused by the oscillatory mower amounted to $1,31 \%$ of the yield and $3,25 \%$ by the rotary mower. Potkonjak et al. [18] reported that the oscillatory mower achieved a maximum speed of 8,82 $\mathrm{km} / \mathrm{h}$ during testing, but with highly increased losses - the specific total mowing losses of the green mass amounted to $1,27 \%$ of the yield, with a maximum productivity of 1,06 ha/h.

\section{MATERIALS AND METHOD}

This study focuses on an important stage of alfalfa hay preparation in the central Serbia region, which is most commonly performed by oscillatory and rotary mowers aggregated with tractors. They are generally characterized by low output and high specific fuel consumption. The objective of the present study was to provide additional information on the optimal choice of mowers and their working parameters for alfalfa grown under dryland conditions in the region of central Serbia.

\subsection{Plant Materials, Climate Conditions and Location}

The mowers were tested during the mowing of alfalfa NS Median ZMS $V$ medium-early matured crop variety. Fast growth and high regeneration power of this variety allows its frequent mowing, up to 4 or maximum 5 cuts per year [19].

The experiment was performed in Kruševac (a sub-

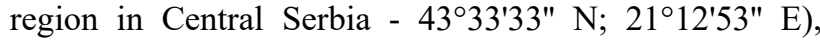
during the three seasons: 2014, 2015 and 2016. Bearing in mind that the first cut is the most important, the tests were focused on mowing in the early flowering stage, in the first cut in late May. The alfalfa plants were in the fourth (2014), fifth (2015) and sixth season (2016) of three-cuts growing system without irrigation - the so-called dryland conditions.

\subsection{Experimental Setup}

Three different types of mowing machines were tested in this study. In the remainder of this paper, they are referred to as mowers $A, B$, and $C: A$ - a self-propelled oscillatory mower-conditioner; $B$ - an oscillatory mower with cutter bar, and $C$ - a rotary mower with drums.

The self-propelled mower-conditioner $A$ is powered by a $75 \mathrm{~kW}$ four-stroke diesel engine. The mowing device is based on an oscillating mower with a classic cutting apparatus with a working width of $4,27 \mathrm{~m}$. The crushing device contains two steel grate rollers, the upper positioned slightly forward with respect to the lower roller. The mowed green mass passes between them, forming a thin layer. In this way, a uniform breaking and slight crushing of green mass can be achieved, enabling uniform drying of the plant (crop) green mass. The mower $B$ is a tractor rear mounted oscillatory mower with a classic cutting apparatus, with a working width of $1,53 \mathrm{~m}$. The third mower, tractor rear mounted rotary mower with drums $C$, was equipped with two drums, each having three blades allowing the blade rotation speed between $60 \mathrm{~m} / \mathrm{s}$ and 80 $\mathrm{m} / \mathrm{s}$, with a working width of $1,65 \mathrm{~m}$. The oscillatory mower was aggregated with a $29 \mathrm{~kW} 4 \times 2$ tractor, while the rotary mower was powered by a $42,6 \mathrm{~kW} 4 \times 2$ tractor.

\subsection{Plant Biomass Measurement}

Within the limitations of the extensive alfalfa growing conditions, the average yield during the first experimental year and the first cut amounted to $3,7 \mathrm{t} \cdot \mathrm{ha}^{-1}$ and about 3,5 $\mathrm{t} \cdot \mathrm{ha}^{-1}$ in the second and third year of experimental work. The yield of green mass was determined within three probes each having three repetitions of alfalfa mass collected from one square meter of the experimental plot, and then recalculated per area of one hectare [4, 20]. All mass samples were measured using the analytical electronic scale Mettler Toledo JS1603C.

\subsection{Exploitation Parameters}

The working parameters of the mowers tested were measured within three probes (each having three repetitions). The working speed was determined for each mower using the standard chronometric method measuring the time interval of machine travelling along the $500 \mathrm{~m}$ long experimental trace. The length of trace was measured using a laser distance meter PCE LDM 50, while the chronometry was based on a digital chronometer TFA Dostmann Triple Time XL-Digitaler 3-fach Timer [20]. Fuel consumption was measured using the volumetric method, the so called "top-up" method [21] and verified using the fuel ultrasonic flow meter PCE-TDS 100HS [20].

The performance of the mowers tested was evaluated on the basis of the effective working swath, the cutting heights of the alfalfa stems and mowing losses, assuming the optimal cutting height for alfalfa crop of $6 \mathrm{~cm}$. Wiersma and Wiederholt [13] reported that cutting heights influence nutritional quality of alfalfa hay - minimum allowed cutting height is 2 inches $(5,1 \mathrm{~cm})$. Some researchers, such as [12], recommended a minimum value of 3-4 inches $(7,6$ $\mathrm{cm}$ and 10,2 cm), while [22] accepted the value of $7 \mathrm{~cm}$. The average cutting heights of alfalfa stems were evidenced at the site by direct measurement over the corresponding rectangular control surfaces, for each test having 3 repetitions [4]. The average values of each sample collected were determined based on these experimental data. Mowing losses were evaluated following widely accepted protocols defined by [4] as well as [23]. They were measured over the surface defined by the adequate swath width of each mower tested, being one meter long, using an appropriate rectangular frame.

The effective (realized) swath widths were determined by a direct measurement, while the coefficients $\beta_{i}(i=1,2$, $3)$ of the swath width utilization efficiencies were calculated as the ratio of the nominal and effective (realized) swath widths. The productivity $\left(W_{\mathrm{pr}}\right)$ of the mowers was calculated using the equation: 
$W_{\mathrm{pr}}=0,1 \cdot v \cdot S \cdot \beta \cdot T_{\mathrm{pr}}, \mathrm{ha} / \mathrm{h}$

where: $v$ is the constant working speed defined in the experimental plan, $\mathrm{km} / \mathrm{h} ; S$ is the effective swath width, $\mathrm{m}$; $\beta$ is the coefficient of swath width exploitation; $T_{\mathrm{pr}}$ is coefficient of working time utilization.

\subsection{Statistical Analysis}

The obtained experimental data were processed using the freeware software package R-Statistics, [24]. Following the common practice in the scientific areas of this kind, the normal (Gaussian) distribution of statistical variables was assumed (see [25], among others, for illustration. The analysis of variance $(F$ test $)$ was performed for two factorial experiment based on the experimental year as the first factor and the mower type as the second [26]. Using experimental data based on three repetitions of each measurement, Tukey's multiple range test and coefficient of variation were used to measure the effects of the treatments. The effect of mower working speed on alfalfa cutting height, losses, specific fuel consumption, and productivity were analysed using the linear regression model [26]

\section{RESULTS}

The analysis of variance (F-test) for two factorial experiments (factors: seasons and mowers) demonstrated that the season (i.e., more precisely, the experimental season), as well as the interaction "season $\times$ mower type", had no statistically significant effect on the parameters tested ( $p \geq 0,05)$, Tab. 1 . On the other hand, the mower type tested had a statistically significant $(p \leq 0,001)$ effect on achieved working swath $(S)$, the working speed of mower $(v)$, losses due to cutting height $\left(L_{\text {cut }}\right)$, chopping losses ( $\left.L_{\text {chop }}\right)$, and productivity $\left(W_{\mathrm{pr}}\right)$, as well as on the cutting height $\left(H_{\text {cut }}\right)(p \leq 0,01)$, and specific fuel consumption $\left(F_{\text {sc }}\right)$ $(p \leq 0,05)$, Tab. 1 .

Experimental results of the three mowers test are presented and summarized in Tab. 2. In addition to the original data, the mean \pm standard deviation values are also presented for each type of mowers. The coefficients of variance are also given. Using acquired experimental data based on three repetitions of each measurement, Tukey's multiple range test and coefficient of variation were used to evaluate the effects of the treatments.

According to experimental results, the mower $A$ achieved significantly $(p \leq 0,05)$ higher values of $H_{\text {cut }}, L_{\text {cut }}$, $T_{\mathrm{pr}}$ and $W_{\mathrm{pr}}$, for each experimental season compared to the two mowers $(B$ and $C$ ). The values of $\beta$, achieved by the mower $A$, were also significantly higher $(p \leq 0,05)$ in comparison to the mower $B$ for all three experimental seasons and the mower $C$ for one season only. The statistically significant difference of $\beta$ values between the mowers $A$ and $C$ was not found in other two seasons ( $p>$ $0,05)$, as it is presented in the Tab. 2. The mower $C$ achieved significantly $(p \leq 0,05)$ higher value for $v, L_{\text {chop }}$ than the mowers $A$ and $B$. Regarding $F_{\mathrm{sc}}$, the mower $C$ was characterized by significantly $(p \leq 0,05)$ higher values than the mower $A$ in all three seasons and the mower $B$ in one season only. For the remaining two experimental seasons, no statistically significant difference was found between the mowers $C$ and $B$, as it can be seen in Tab. 2 .

Table 1 Analysis of variance (ANOVA) for the hay mowing machines $(A)$ and vegetation season $(B)$

\begin{tabular}{|l|c|c|c|c|c|c|c|c|c|c|c|}
\hline \multicolumn{1}{|c|}{ Factor/Property } & $d f$ & $S / \mathrm{m}$ & $\beta$ & $H_{\text {cut }} / \mathrm{cm}$ & $v / \mathrm{km} / \mathrm{h}$ & $L_{\text {cut }} / \%$ & $L_{\text {chop }} / \%$ & $T_{\mathrm{pr}}$ & $W_{\mathrm{pr}} / \mathrm{ha} / \mathrm{h}$ & $F_{\text {sc }} / \mathrm{L} / \mathrm{ha}$ \\
\hline Mower type $-A$ & 2 & $* * *$ & n.s. & $* *$ & $* * *$ & $* * *$ & $* * *$ & n.s. & $* * *$ & $*$ & n.s. \\
\hline Season $-B$ & 4 & n.s. & n.s. & n.s. & n.s. & n.s. & n.s. & n.s. & n.s. \\
\hline Interaction $A \times B$ & 4 & n.s. & n.s. & n.s. & n.s. & n.s. & n.s. & n.s. & n.s. & n.s. \\
\hline
\end{tabular}

F test statistical significance levels: ${ }^{*} p \leq 0,05 ;{ }^{* *} p \leq 0,01 ;{ }^{* * *} p \leq 0,001 ;$ n.s. - not significant $(p \geq 0,05)$

Maximum value of the coefficient of swath width exploitation $(\beta)$ of 0,96 (Tab. 2) was achieved by the selfpropelled mower-conditioner $A$, during the first $(S=4,11$ $\mathrm{m})$ and the second experimental season $(S=4,08 \mathrm{~m})$. The minimum value of $0,90(S=1,39 \mathrm{~m})$ was evidenced during the testing of oscillatory mower $B$, in the third experimental season (Tab. 2). In addition to the values of $\beta$, Tab. 2 also summarizes a wide variety of other results of mower testing, illustrating the quality of their work.

It is recognized worldwide that the working speed of a mower applied affects not only the mowing process, but also the quality of final product (hay, haylage), production economy and sustainability, etc. [4, 27, 28]. Therefore, the experimental data obtained were processed using the linear regression method to shed light on the relationships between working parameters of the mowers tested and their working speeds. Output results are listed in Tab. 2 and illustrated in Figs. 1 to 6.

As it can be seen in Tab. 2 and Fig. 1, the mower working speed influences the cutting height of alfalfa stem. During the testing of a rotary mower with drums, [16] revealed that the smallest cutting height of $5,15 \mathrm{~cm}$ was achieved at a working speed of $5,89 \mathrm{~km} / \mathrm{h}$, while the maximum height of $6,50 \mathrm{~cm}$ was achieved at a mower speed of $9,29 \mathrm{~km} / \mathrm{h}$.

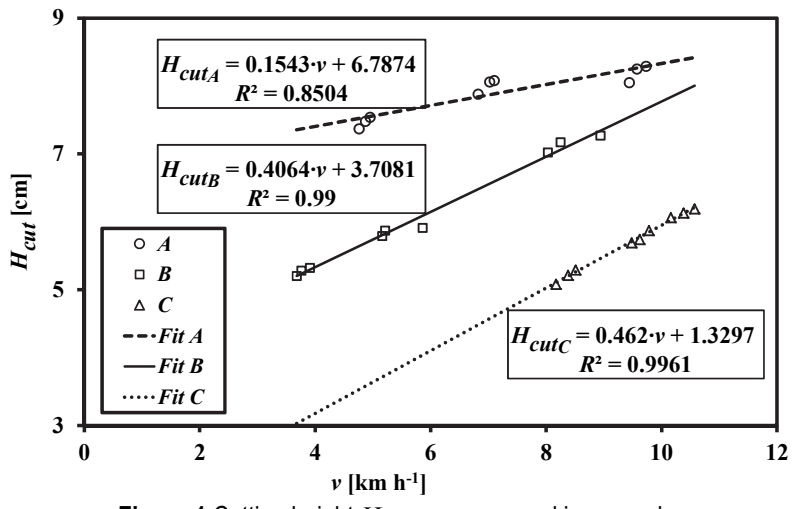

Figure 1 Cutting height $H_{\text {cut }}$ vs. mower working speed $v$

The tests results presented in this study demonstrate that the highest cutting height of $8,3 \mathrm{~cm}$ was achieved by the self-propelled mower-conditioner $A$ during the third experimental season at a working speed of $9,73 \mathrm{~km} / \mathrm{h}$. The rotary mower with drum $C$ achieved the minimum cut-off height of $5,1 \mathrm{~cm}$ in the first experimental season, at a 
working speed of $8,17 \mathrm{~km} / \mathrm{h}$. The results of this study are in line with the previous findings $[13,22]$. Additionally, Fig. 1 clearly shows that the height of the alfalfa stem cutting increased linearly with an increase in the working speed. This increase was most exposed in the case of the mower $C$ (regression slope coefficient was $b=0,462$ ) and least for the mower $A-b=0,1543$, which is therefore far preferable in this respect. The numerical values of the $R^{2}$ factor indicate a strong dependence for the mower $A\left(R^{2}=\right.$ $0,8504)$ and very strong for the mowers $B\left(R^{2}=0,99\right)$ and $C\left(R^{2}=0,9961\right)$.

The losses resulting from an inadequate cutting height of the alfalfa stem $\left(L_{\text {cut }}\right)$ are presented in Tab. 2 and Fig. 2. The cutting losses are a direct consequence of inadequate cutting of alfalfa stems, that is, inappropriate cutting height $\left(H_{\text {cut }}\right)$ which is different from the optimal. Bearing in mind that the cutting height increased linearly as the working speed $(v)$ of all three mowers $(A, B$ and $C$ ) increased, the analogue situation was expected and evidenced in the case of cutting losses.

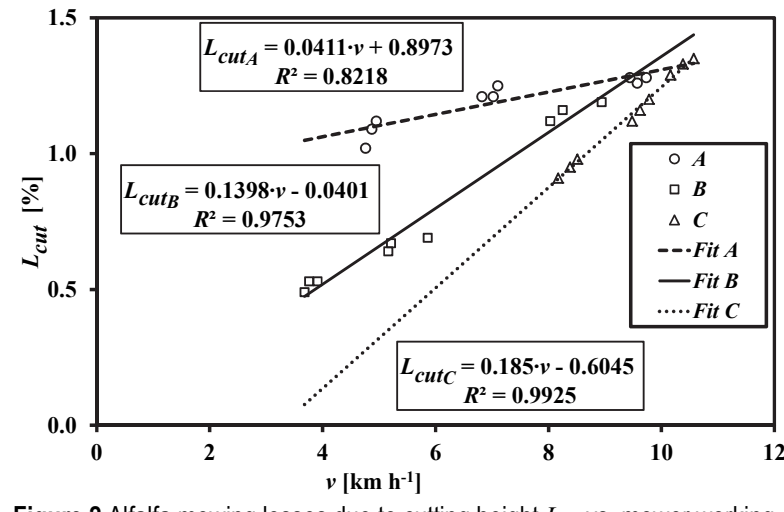

Figure 2 Alfalfa mowing losses due to cutting height $L_{\text {cut }}$ vs. mower working speed $v$

Table 2 Experimental results for the main research parameters

\begin{tabular}{|c|c|c|c|c|c|c|c|c|c|c|c|c|c|}
\hline \multirow{3}{*}{ Param. } & \multirow{3}{*}{ Mower } & \multicolumn{4}{|c|}{ Season I. } & \multicolumn{4}{|c|}{ Season II. } & \multicolumn{4}{|c|}{ Season III. } \\
\hline & & \multicolumn{3}{|c|}{ Repetition } & $\bar{X}_{ \pm \sigma}$ & \multicolumn{3}{|c|}{ Repetition } & $\bar{X}_{ \pm \sigma}$ & \multicolumn{3}{|c|}{ Repetition } & \multirow{2}{*}{$\begin{array}{r}\bar{X} \pm \sigma \\
C V / \% \\
\end{array}$} \\
\hline & & 1 & 2 & 3 & $C V / \%$ & 1 & 2 & 3 & $\mathrm{CV} / \%$ & 1 & 2 & 3 & \\
\hline Yield & - & 3,65 & 3,80 & 3,65 & - & 3,40 & 3,55 & 3,55 & - & 3,50 & 3,45 & 3,55 & - \\
\hline$h / \mathrm{cm}$ & - & 79,0 & 82,0 & 78,0 & - & 78,0 & 76,0 & 72,0 & - & 74,0 & 68,0 & 77,0 & - \\
\hline \multirow{4}{*}{$\begin{array}{c}v \\
/ \mathrm{km} / \mathrm{h}\end{array}$} & $A$ & 4,76 & 6,82 & 9,44 & $7,01 \pm 2,34^{b}$ & 4,87 & 7,02 & 9,57 & $7,15 \pm 2,23^{b}$ & 4,9 & 7,10 & 9,73 & $7,26 \pm 2,38^{b}$ \\
\hline & $B$ & 3,68 & 5,16 & 8,03 & $5,62 \pm 2,21^{\mathrm{c}}$ & 3,76 & 5,21 & 8,25 & $5,74 \pm 2,29^{c}$ & 3,91 & 5,86 & 8,94 & $5,90 \pm 2,42^{\mathrm{c}}$ \\
\hline & $C$ & 8,17 & 9,48 & 10,16 & $9,27 \pm 1,01^{\mathrm{a}}$ & 8,38 & 9,62 & 10,38 & $9,46 \pm 1,31^{\mathrm{a}}$ & 8,5 & 9,78 & 10,57 & $9,62 \pm 1,09^{\mathrm{a}}$ \\
\hline & $\mathrm{CV} / \%$ & - & - & - & 25,24 & - & - & - & 25,21 & - & - & - & 24,79 \\
\hline \multirow{4}{*}{$\begin{array}{l}H_{\text {cut }} \\
/ \mathrm{cm}\end{array}$} & $A$ & 7,37 & 7,88 & 8,05 & $7,77 \pm 1,25^{\mathrm{a}}$ & 7,48 & 8,06 & 8,25 & $7,93 \pm 0,99^{\mathrm{a}}$ & 7,54 & 8,08 & 8,29 & $7,97 \pm 0,89^{\mathrm{a}}$ \\
\hline & $B$ & 5,20 & 5,79 & 7,02 & $6,00 \pm 1,46^{\mathrm{b}}$ & 5,28 & 5,87 & 7,17 & $6,11 \pm 1,13^{b}$ & 5,32 & 5,91 & 7,27 & $6,17 \pm 1,02^{b}$ \\
\hline & $C$ & 5,08 & 5,69 & 6,06 & $5,61 \pm 1,02^{\mathrm{c}}$ & 5,21 & 5,74 & 6,13 & $5,69 \pm 0,11^{\mathrm{c}}$ & 5,29 & 5,87 & 6,19 & $5,78 \pm 0,91^{\mathrm{c}}$ \\
\hline & $\mathrm{CV} / \%$ & - & - & - & 17,82 & - & - & - & 18,10 & - & - & - & 17,59 \\
\hline \multirow{4}{*}{$\beta$} & $A$ & 0,99 & 0,95 & 0,94 & $0,96 \pm 0,25^{\mathrm{a}}$ & 0,97 & 0,96 & 0,94 & $0,96 \pm 0,28^{\mathrm{a}}$ & 0,96 & 0,95 & 0,94 & $0,95 \pm 0,21^{\mathrm{a}}$ \\
\hline & $B$ & 0,96 & 0,94 & 0,91 & $0,94 \pm 0,31^{\mathrm{c}}$ & 0,95 & 0,92 & 0,90 & $0,92 \pm 0,31^{b}$ & 0,93 & 0,90 & 0,87 & $0,90 \pm 0,33^{b}$ \\
\hline & $C$ & 0,96 & 0,94 & 0,93 & $0,95 \pm 0,41^{\mathrm{b}}$ & 0,96 & 0,94 & 0,92 & $0,94 \pm 0,38^{\mathrm{ab}}$ & 0,94 & 0,93 & 0,91 & $0,92 \pm 0,29^{\mathrm{ab}}$ \\
\hline & $C V / \%$ & - & - & - & 1,05 & - & - & - & 2,12 & - & - & - & 2,72 \\
\hline \multirow{4}{*}{$\begin{array}{l}L_{\text {cut }} \\
/ \%\end{array}$} & $A$ & 1,02 & 1,21 & 1,28 & $1,17 \pm 0,78^{\mathrm{a}}$ & 0,36 & 0,28 & 0,25 & $0,30 \pm 0,77^{b}$ & 0,37 & 0,26 & 0,26 & $0,30 \pm 1,02^{b}$ \\
\hline & $B$ & 0,49 & 0,64 & 1,12 & $0,75 \pm 0,69^{c}$ & 0,41 & 0,37 & 0,32 & $0,37 \pm 0,81^{b}$ & 0,44 & 0,4 & 0,29 & $0,38 \pm 0,98^{b}$ \\
\hline & $C$ & 0,91 & 1,12 & 1,29 & $1,11 \pm 0,81^{b}$ & 2,16 & 1,72 & 1,63 & $1,84 \pm 0,79^{\mathrm{a}}$ & 2,10 & 1,66 & 1,59 & $1,78 \pm 0,79^{\mathrm{a}}$ \\
\hline & $\mathrm{CV} / \%$ & - & - & - & 22,49 & - & - & - & 21,12 & - & - & - & 21,73 \\
\hline \multirow{4}{*}{$\begin{array}{l}L_{\text {chop }} \\
/ \%\end{array}$} & $A$ & 0,33 & 0,26 & 0,24 & $0,28 \pm 0,99^{b}$ & 0,36 & 0,28 & 0,25 & $0,30 \pm 0,77^{\mathrm{b}}$ & 0,37 & 0,26 & 0,26 & $0,30 \pm 1,02^{b}$ \\
\hline & $B$ & 0,38 & 0,34 & 0,29 & $0,34 \pm 1,06^{\mathrm{b}}$ & 0,41 & 0,37 & 0,32 & $0,37 \pm 0,81^{\mathrm{b}}$ & 0,44 & 0,4 & 0,29 & $0,38 \pm 0,98^{\mathrm{b}}$ \\
\hline & $C$ & 2,11 & 1,68 & 1,57 & $1,79 \pm 0,89^{\mathrm{a}}$ & 2,16 & 1,72 & 1,63 & $1,84 \pm 0,79^{\mathrm{a}}$ & 2,10 & 1,66 & 1,59 & $1,78 \pm 0,79^{\mathrm{a}}$ \\
\hline & $\mathrm{CV} / \%$ & - & - & - & 106,40 & - & - & - & 103,90 & - & - & - & 101,50 \\
\hline \multirow{4}{*}{$T_{\mathrm{pr}}$} & $A$ & 0,86 & 0,87 & 0,89 & $0,88 \pm 0,12^{\mathrm{a}}$ & 0,86 & 0,88 & 0,90 & $0,88 \pm 0,16^{\mathrm{a}}$ & 0,87 & 0,88 & 0,90 & $0,88 \pm 0,12^{\mathrm{a}}$ \\
\hline & $B$ & 0,82 & 0,84 & 0,86 & $0,84 \pm 0,21^{\mathrm{b}}$ & 0,83 & 0,85 & 0,85 & $0,84 \pm 0,12^{\mathrm{b}}$ & 0,83 & 0,84 & 0,86 & $0,84 \pm 0,19^{b}$ \\
\hline & $C$ & 0,82 & 0,85 & 0,87 & $0,85 \pm 0,31^{\mathrm{b}}$ & 0,83 & 0,85 & 0,87 & $0,85 \pm 0,12^{\mathrm{b}}$ & 0,83 & 0,84 & 0,88 & $0,85 \pm 0,31^{\mathrm{b}}$ \\
\hline & $\mathrm{CV} / \%$ & - & - & - & 2,44 & - & - & - & 2,43 & - & - & - & 2,42 \\
\hline \multirow{4}{*}{$\begin{array}{c}W_{\mathrm{pr}} \\
/ \mathrm{ha} / \mathrm{h}\end{array}$} & $A$ & 1,72 & 2,41 & 3,36 & $2,50 \pm 0,10^{\mathrm{a}}$ & 1,73 & 2,52 & 3,46 & $2,57 \pm 0,16^{\mathrm{a}}$ & 1,77 & 2,53 & 3,50 & $2,59 \pm 0,21^{\mathrm{a}}$ \\
\hline & $B$ & 0,44 & 0,62 & 0,97 & $0,68 \pm 0,21^{\mathrm{c}}$ & 0,45 & 0,62 & 0,97 & $0,68 \pm 0,12^{\mathrm{c}}$ & 0,46 & 0,68 & 1,03 & $0,69 \pm 0,18^{c}$ \\
\hline & $C$ & 1,06 & 1,25 & 1,36 & $1,23 \pm 0,18^{b}$ & 1,10 & 1,27 & 1,37 & $1,25 \pm 0,23^{b}$ & 1,10 & 1,27 & 1,40 & $1,26 \pm 0,21^{\mathrm{b}}$ \\
\hline & $\mathrm{CV} / \%$ & - & - & - & 63,50 & - & - & - & 64,63 & - & - & - & 64,43 \\
\hline \multirow{4}{*}{$\begin{array}{c}F_{\mathrm{sc}} \\
/ \mathrm{L} / \mathrm{ha}\end{array}$} & $A$ & 2,81 & 2,15 & 2,07 & $2,29 \pm 0,40^{b}$ & 2,69 & 2,23 & 2,08 & $2,29 \pm 0,38^{b}$ & 2,63 & 2,26 & 2,06 & $2,27 \pm 0,41^{\mathrm{b}}$ \\
\hline & $B$ & 2,95 & 2,44 & 2,3 & $2,51 \pm 0,48^{\mathrm{ab}}$ & 3,08 & 2,18 & 2,18 & $2,37 \pm 0,51^{\mathrm{ab}}$ & 2,98 & 2,22 & 2,18 & $2,38 \pm 0,43^{b}$ \\
\hline & $C$ & 2,93 & 2,77 & 2,63 & $2,76 \pm 0,31^{\mathrm{a}}$ & 2,99 & 2,75 & 2,64 & $2,77 \pm 0,47^{\mathrm{a}}$ & 3,03 & 2,75 & 2,66 & $2,80 \pm 0,51^{\mathrm{a}}$ \\
\hline & $\mathrm{CV} / \%$ & - & - & - & 9,33 & - & - & - & 10,38 & - & - & - & 11,26 \\
\hline
\end{tabular}

$v$ - working speed; $H_{\text {cut }}$ - cutting height; $\beta$ - coefficient of swath width exploitation; $L_{\text {cut }}$ - cutting losses; $L_{\text {chop }}$ - chopping losses; $F_{\text {sc }}$ - specific fuel consumption; $T_{\text {pr }}$ - coefficient of working time utilization; $W_{\text {pr }}$ - productivity; $A$ - self-propelled oscillatory mower-conditioner; $B$ - oscillatory mower with cutter bar; $C$ - rotary mower with drums .

The first mower, type $A$, was the least sensitive to the working speed (the regression slope coefficient was $b=$ $0,0411)$, while the most sensitive to the speed variations was the mower $C(b=0,185)$. Similar to cutting height, this dependence was strong for the self-propelled mower with conditioner $A\left(R^{2}=0,8218\right)$ and very strong for the mowers $B\left(R^{2}=0,9753\right)$ and $C\left(R^{2}=0,9925\right)$. The highest value of losses $\left(L_{\text {cut }}\right)$ due to cutting height amounted to $1,35 \%$ of the yield, when operating the rotary mower with drums $C$ in the third experimental season at a speed of $10,57 \mathrm{~km} / \mathrm{h}$, and a minimum of $0,49 \%$ when operating the oscillatory mower $B$ in the first season at a speed of $3,68 \mathrm{~km} / \mathrm{h}$.

The highest chopping losses $\left(L_{\text {chop }}\right)$ were evidenced during the testing of the rotary mower with drums $C$ in the second experimental year $(2,16 \%)$ at a working speed of $8,38 \mathrm{~km} / \mathrm{h}$, while they were lowest when testing the selfpropelled mower-conditioner $A$ in the first experimental season (0,24\%) at a speed of 9,44 km/h (Tab. 2 and Fig. 3). 
Chopping losses decreased linearly for all three mowers with an increase in working speed - most rapidly for the mower $C$ (regression slope coefficient $b=-0,2619$ ), while decreasing slope was smaller and nearly identical for the mowers aggregated with tractors $B(b=-0,0225)$ and $A(b$ $=-0,021)$. This relationship was medium strong for the tested mowers $A\left(R^{2}=0,751\right)$ and $B\left(R^{2}=0,7502\right)$, and strong for the mower $C\left(R^{2}=0,9152\right)$.

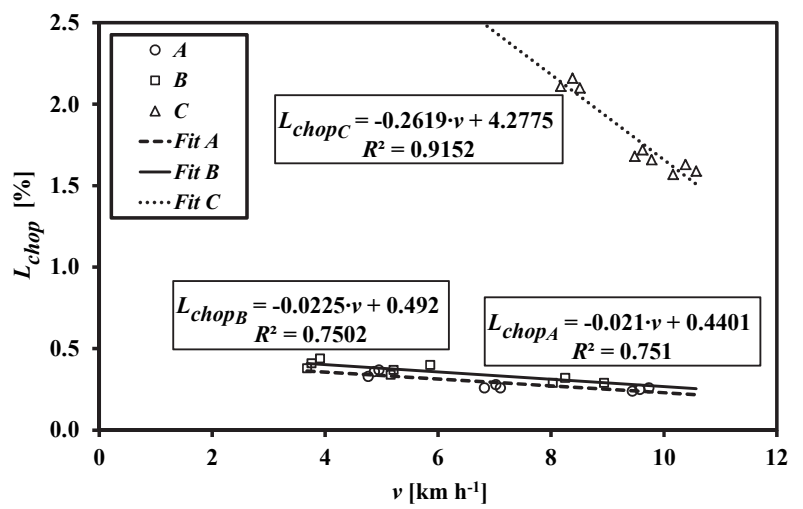

Figure 3 Mowing losses due to chopping $L_{\text {chop }}$ Vs. mower working speed $v$

The value of the coefficient of production working time utilization $\left(T_{\mathrm{pr}}\right)$ is calculated from the ratio of technologically useful time $\left(T_{1}\right)$ and production time $\left(T_{2}\right)$ :

$T_{\mathrm{pr}}=T_{1} / T_{2}<1$

Technologically useful time $T_{1}$ is the time of performing mowing operation. In addition to technologically useful time, the production time $T_{2}$ also includes the auxiliary time, lost due to any machine downtime. The highest value of this parameter $(0,90)$ was evidenced during the testing of the self-propelled mowerconditioner $A$ in the second and third experimental season, while the minimum value $(0,82)$ was evidenced during the testing of the mowers $B$ and $C$ in the first season (Fig. 4). This dependence was found to be very strong for the mower $A\left(R^{2}=0,918\right)$ and strong for the remaining two mowers $\left(R^{2}=0,8104\right.$ and 0,8952 , for the mowers $B$ and $C$, respectively). An increase in working time utilization coefficient with an increase in mower working speed was the highest for the mower $C(b=0,022)$, while for the other two mowers was smaller and approximately equal $(b=$ 0,0072 and $b=0,0061$, for the mowers $A$ and $B$, respectively).

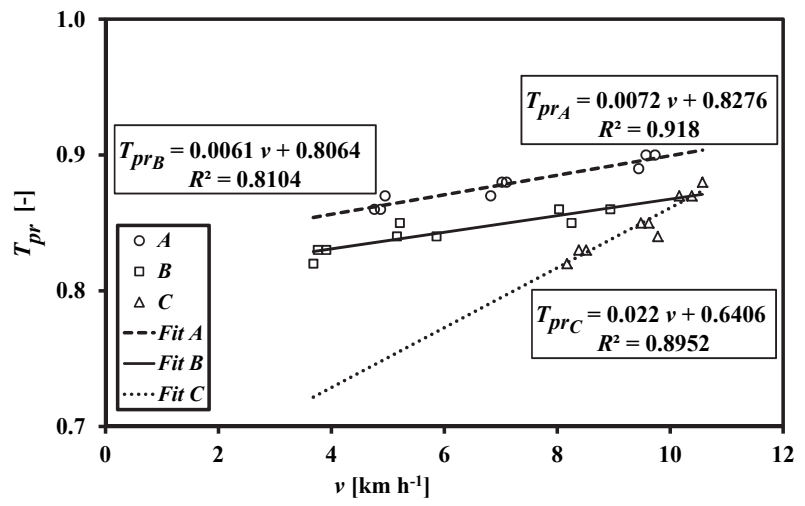

Figure 4 Work time utilization coefficient $T_{\text {pr }}$ vs. mover working speed $v$
The maximum productivity of $3,50 \mathrm{ha} / \mathrm{h}$ was achieved when using the self-propelled mower-conditioner $A$ in the third experimental season at a working speed of $9,73 \mathrm{~km} / \mathrm{h}$ (Tab. 2, Fig. 5). The minimum value of $0,44 \mathrm{ha} / \mathrm{h}$ was achieved by the oscillatory mower $B$ in the first experimental season, at a working speed of $3,68 \mathrm{~km} / \mathrm{h}$. Productivity increased with an increase in operating speed for all three mowers. Very strong dependence was found in all three cases $\left(R^{2}>0,99\right)$. The increase in productivity was the highest for the mower $A(b=0,3606)$ and much lower for the mowers $B(b=0,1159)$ and $C(b=0,1419)$.

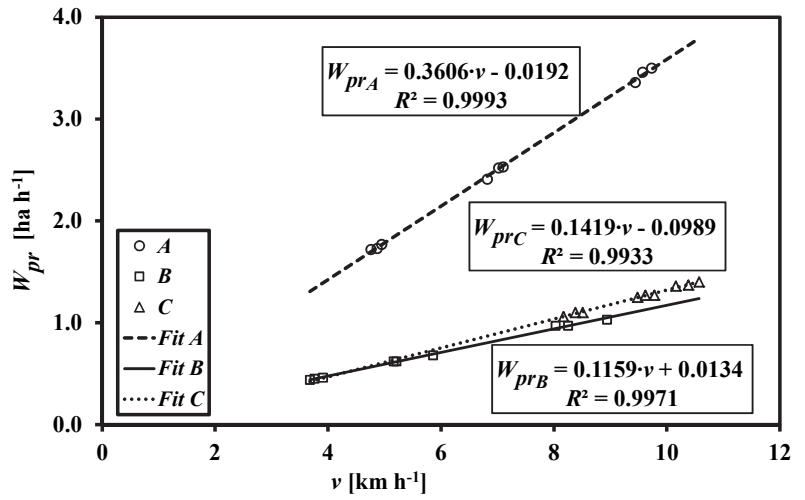

Figure 5 Productivity $W_{\mathrm{pr}}$ vs. mower working speed $v$

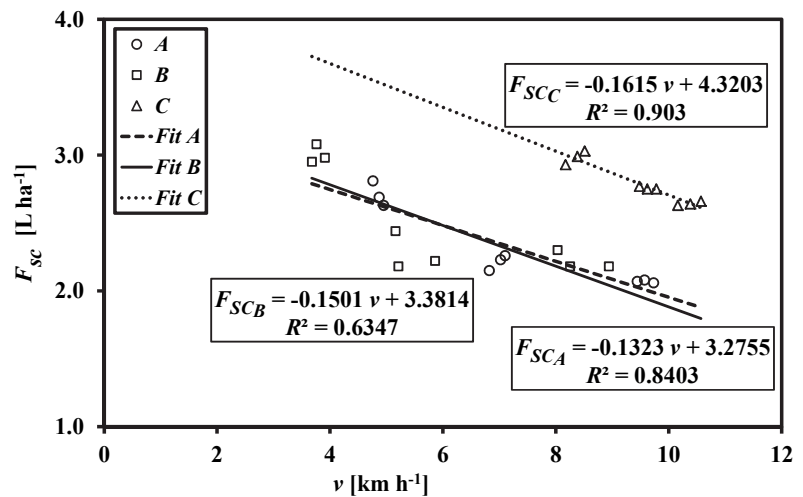

Figure 6 Specific fuel consumption $F_{\text {sc }}$ vs. mower working speed $v$

The self-propelled mower-conditioner $A$ achieved a minimum specific fuel consumption of $2,06 \mathrm{~L} /$ ha in the third experimental season at an average working speed of $9,73 \mathrm{~km} / \mathrm{h}$, while a maximum specific consumption of 3,08 $\mathrm{L} /$ ha was reached by the oscillatory mower $B$ during the second year at an average working speed of $3,76 \mathrm{~km} / \mathrm{h}$ (Tab. 2, Fig. 6). As illustrated in Fig. 6, specific fuel consumption decreases with an increase in working speeds of all three mowers. The regression slope coefficients $b_{i}(i$ $=1,2,3)$ were $-0,1323,-0,1501$, and $-0,1615$, and the $R^{2}$ factors achieved values of $0,8403,0,6347$ and 0,903 for the mowers $A, B$ and $C$, respectively.

\section{DISCUSSION}

In the region of central Serbia, alfalfa is grown on the largest areas under dryland conditions without irrigation $[29,30]$. In this system of alfalfa growing, the first cut is accompanied by the most favourable climatic conditions (air temperature, precipitation and water storage in the soil during winter and spring). In contrast, the second, third, and sometimes even the fourth cut are accompanied by high precipitation deficit [31]. Therefore, in the climatic 
conditions of Serbia specified with Koppen Climate Classification [32], three, rarely four cuts are most commonly realized. The first crop obviously has a green mass yield of $47 \%$ to $51 \%$ or $7,94 \mathrm{t} / \mathrm{ha}$ of dry matter yield. On the other hand, alfalfa vegetation period was affected by a winter precipitation deficit and high rainfall in the middle of the year (which is generally rare). Consequently, the yield of green mass participated between $31 \%$ and 32 $\%$, or $5,11 \mathrm{t} /$ ha of dry matter in the first cut [33]. The rainfall and monthly temperatures distributions in Serbia are similar to those in Bulgaria [30]. However, the first cut in Greece occurs under less favourable rainfall-totemperature ratios [29]. Therefore, the participation of the first cut in the total yield of alfalfa is dominant, which motivated the authors of this study to focus on the analysis of the first cut. The analysis of variance revealed that the season factor had no significance as well as the interaction of season-machine factors. In contrast, the type of mower had statistically very significant dependence.

An increase in the working speed of all machines caused an increase in the cutting height, as has been previously reported by other researchers $[12,22]$. In this case, the lowest regression slope coefficient was observed for the mower $A$, and the highest for the mower $C$, indicating that the rotary mower is the highest sensitive machine with respect to working speed. The mower $C$ achieved a cutting height of $6,2 \mathrm{~cm}$ at a speed of 10,57 $\mathrm{km} / \mathrm{h}$, which is generally in line with the previous results $[13,22]$. It should also be mentioned that the mowers $A$ and $B$ achieved this level of cutting height at speeds which were $20-40 \%$ lower than the speeds of the mower $C$ (Tab. 2).

The cutting losses $\left(L_{\text {cut }}\right)$ are directly related to deviations of the cutting height $\left(H_{\text {cut }}\right)$ from the optimal. Bearing in mind that an increase in cutting height with higher working speeds ( $v)$ was evidenced for all three mowers, it was logical that the cutting losses would increase with higher working speeds. Fig. 2 clearly illustrates that the mower $C$ was characterised with the smallest cutting losses, while the highest losses of this kind were evidenced for the mower type $A$. Measurements of chopping losses $\left(L_{\text {chop }}\right)$ pointed out the disadvantage of the mower $C$, which had the highest losses, even up to about 6 times higher when compared with the corresponding losses of the mower $A$ (Fig. 3). Similar results have been reported by other researchers, [20]. This finding is a clear indicator of the drawback of rotary mowers in relation to standard oscillatory mowers.

The productivity $\left(W_{\mathrm{pr}}\right)$ of the mower is directly proportional to the working speed $(v)$, Fig. 5, and to the effective width of the working swath $(S \cdot \beta)$. The highest productivity of $3,50 \mathrm{ha} / \mathrm{h}$ was reached by the mower $A$, while the mowers $B$ and $C$ reached the maximum productivity of only $1,03 \mathrm{ha} / \mathrm{h}$ and $1,4 \mathrm{ha} / \mathrm{h}$, respectively. This means that maximum productivity of mowers $B$ and $C$ was 3,4 and 2,5 times smaller (respectively) than that reached by the mower $A$.

Fuel consumption per hectare, i.e. specific fuel consumption $\left(F_{\mathrm{sc}}\right)$ is inversely proportional to mower working speed $(v)$ and productivity $\left(W_{\mathrm{pr}}\right)$. These results are in line with the previous results [14]. As presented in Tab. 2 and Fig. 6, the mower $C$ had the highest values of fuel consumption ranging between $2,63 \mathrm{~L} / \mathrm{ha}$ and $3,03 \mathrm{~L} / \mathrm{ha}$, while the mowers $A$ and $B$ had lower but generally similar specific fuel consumption (between 2,06 and 3,08 L/ha). However, the $R^{2}$ factor reached the highest value $(0,903)$ for the regression line describing relationship $F_{\mathrm{sc}}=F_{\mathrm{sc}}(v)$ of the mower $C$, indicating a very strong dependence (Fig. $6)$. A weaker dependence was found for the mowers $A$ and $B$ ( $R^{2}$ factors were 0,8403 and 0,6347 , respectively). With respect to $F_{\mathrm{sc}}=F_{\mathrm{sc}}(v)$, the regression slope coefficients were similar for all mowers: $-0,1323,-0,1501$ and $-0,1615$, for machine $A, B$ and $C$, respectively (Fig. 6).

\section{CONCLUSION}

This study is based on three-year comparison tests of a self-propelled mower - type $A$, a tractor propelled oscillatory mower with cutter bar - type $B$ and a rotary mower with drums - type $C$ aggregated with a tractor, used for alfalfa cultivated under dryland conditions in central Serbia, specified with Koppen Climate Classification [32]. It was observed that the proper choice of the mower type and design, as well as their working parameters, have strongly affected the productivity and efficiency of alfalfa hay preparation. The self-propelled mower $A$, achieved high average productivity value of $2,55 \mathrm{ha} / \mathrm{h}$, much higher with respect to the other two types of mowers: $B 0,68 \mathrm{ha} / \mathrm{h}$, and $C 1,27 \mathrm{ha} / \mathrm{h}$.

Specific fuel consumption, as an element of mower work economy and environment protection, was the smallest for the mower type $A(2,28 \mathrm{~L} / \mathrm{h}$ in average), followed by the mower $B(2,42 \mathrm{~L} / \mathrm{h}$ in average $)$ and $C(2,78$ $\mathrm{L} / \mathrm{h})$ in average. In addition, an increase in the working speed had the smallest reduction in fuel consumption in the case of mower $A$ with regression coefficient $b=-0,1323$, which puts it in a less favourable position compared to the mower $B$ (regression coefficient $b=-0,1501$ ), and in a much less favourable position in relation to the mower $C$ characterized by the highest reduction in fuel consumption (regression coefficient $b=-0,1615$ ).

Generally, the results of our comparative analysis confirmed the superiority of the self-propelled mower $A$ over the mowers $B$ and $C$; therefore, the widespread use of this type of mower in the mowing and storage process of alfalfa hay under dryland conditions in central Serbia is preferred.

\section{Acknowledgments}

The investigation presented in this paper is a part of the project entitled "Improvement of biotechnological procedures as a function of rational utilization of energy, agricultural products productivity and quality increase" funded by the Ministry of Education and Scientific and Technological Development of the Republic of Serbia, grant No TR-31051 within the framework of the contract for the realization and financing of scientific research work in 2020 between the Faculty of Agriculture in Belgrade and the Ministry, contract registration number: 451-0368/2020-14200116.

\section{REFERENCES}

[1] Fanlo, R., Chocarro, C., Lloveras, J., Ferran, X., Serra, J., Salvia, J., Muñoz, F., Andueza, J., \& Delgado, I. (2006). Alfalfa Production and Quality in Northeast Spain. Proceedings of the $21^{\text {st }}$ General Meeting of the European Grassland Federation Badajoz Spain, 261-264.

[2] Lüscher, A., Mueller-Harvey, I., Soussana, J. F., Rees, R. M., \& Peyraud, J. L. (2014). Potential of Legume-Based Grassland-Livestock Systems in Europe: A review. Grass Forage Science, 69(2), 206-228. 
https://doi.org/10.1111/gfs.12124

[3] Anonymous, (2019). Statistical Yearbook of the Republic of Serbia 2019. Statistical Office of the Republic of Serbia.

[4] Rotz, C. A. \& Abrams, S. M. (1988). Losses and Quality Changes during Alfalfa Hay Harvest and Storage. Trans ASAE, 31(2), 350-355. https://doi.org/10.2134/1994.foragequality.c20

[5] Belesky, D. P. \& Fedders, J. M. (1997). Residue Height Influences Stand Dynamics of Alfalfa Grown on a Shallow Soil. Agronomy Journal, 89(6), 975-980. https://doi.org/10.2134/agronj1997.00021962008900060021x

[6] Savoie, P., Caron, E., \& Tremblay, G. F. (2011). Control of Losses during the Haymaking Process. Proceeding, International Symposium on Forage Quality and Conservation, 2, 143-164.

[7] Orloff, S. \& Putnam, D. (2010). Adjusting Alfalfa Cutting Schedules for Economic Conditions. Proceedings, California Alfalfa \& Forage Symposium and Corn/Cereal Silage Mini-Symposium.

[8] Milić, D., Katanski, S., Karagić, Đ., \& Vasiljević, S. (2016). Alfalfa - The Queen of Forage Plants, a Guide for Successful Production. Institute for Crop Production, Novi Sad.

[9] Karayilanli, E. \& Ayhan, V. (2016). Investigation of Feed Value of Alfalfa (Medicago Sativa L.) Harvested at Different Maturity Stages. Legume Research 39(2), 237-247. https://doi.org/10.18805/r.v0iOF.9292

[10] Ahmad, J., Iqbal, A., Ayub, M., \& Akhtar, J. (2016). Forage Yield Potential and Quality Attributes of Alfalfa (Medicago Sativa L.) Under Various Agro-Management Techniques. Journal of Animal and Plant Sciences, 26(2), 465-474.

[11] Hosseini, S. \& Shamsi, M. (2012). Performance Optimization of a Rotary Mower Using Taguchi Method. Agronomy Research Biosystem Engineering, Special Issue 1, 49-54.

[12] Cutting, B. J. (2004). Conditioning \& Raking for Faster Hay Drying. Ministry of Agriculture and Food, Ontario, Canada.

[13] Wiersma, D. \& Wiederholt, R. (2001). Alfalfa Cutting Height to Maximize Forage Yield and Quality. University of Wisconsin Extension, University of Wisconsin, Team Forage Division of Extension. Wisconsin, Madison, USA.

[14] Rotz, C. A. \& Sprott, D. J. (1984). Drying Rates, Losses and Fuel Requirements for Mowing and Conditioning Alfalfa. Trans ASAE 27(3), 714-720. https://doi.org/10.13031/2013.32859

[15] Rotz, C. A. (2005). Postharvest Changes in Alfalfa Quality. Proceedings "35th California Alfalfa \& Forage Symposium", Visalia, CA, UCC Cooperative Extension, Agronomy Research and Extension Center, 53-262.

[16] Jugović, M., Radivojević, D., Koprivica, R., Šekularac, G., Jakišić, T., \& Lalović, M. (2013). Quality of Rotary Mower SIP RK 135 Mowing Process in Mountainous Area. Proceedings, Fourth International Scientific Symposium "Agrosym 2013", 435-440.

[17] Barać, S., Vuković, A., Milenković, B., \& Biberdžić, M. (2012). Testing Results of Mower with Different Cutting Devices in Alfalfa Mowing. Agricultural Science Research Journal, 4(1), 241-248.

[18] Potkonjak, V., Zoranović, M., \& Anđelković, S. (2009). Exploitation characteristics of different mower types in alfalfa mowing. Contemporary Agricultural Engineering $35(1-2), 73-78$.

[19] Anonymous, (2019). NS Seeds Cultivars of Alfalfa, Institute of Field and Vegetable Crops, Novi Sad, Serbia.

[20] Khalid, A. Al-Gaadi. (2018). Impact of raking and baling patterns on alfalfa hay dry matter and quality losses. Saudi Journal of Biological Sciences, 25, 1040-1048. https://doi.org/10.1016/j.sjbs.2018.02.009

[21] Moitzi, G., Haas, M., Wagentristl, H., Boxberger, J., \& Gronauer, A. (2013). Energy consumption in cultivating and ploughing with traction improvement system and consideration of the rear furrow wheel-load in ploughing. Soil \& Tillage Research, 134, 56-60. https://doi.org/10.1016/j.still.2013.07.006

[22] Sengul, S. (2003). Performance of Some Forage Grasses or Legumes and Their Mixtures under Dry Land Conditions. European Journal of agronomy, 19, 401-409. https://doi.org/10.1016/S1161-0301(02)00132-6

[23] Putnam, D. \& Orloff, S. B. (2002). Hay sampling protocols and a hay sampling certification program. Proceedings of the 32nd California Alfalfa \& Forage Symposium, Reno, Nevada, Department of Agronomy and Range Science Extension, 149-158.

[24] R Core Team R, (2018). R-Statistics, a Language and Environment for Statistical Computing (version 3.4.4). R Foundation for Statistical Computing, Vienna, Austria, Retrieved from https://www. R-project.org

[25] Katanski S. (2017). Yield and quality of alfalfa biomass (Medicago sativa L.) as affected by production management (In Serbian). PhD dissertation, University of Novi Sad, Faculty of Agriculture.

[26] Marques de Sá, P. J. (2007). Applied Statistics using SPSS, STATISTICA, MATLAB and $R$ (second edition). SpringerVerlag, Berlin Heidelberg, 222. https://doi.org/10.1007/978-3-540-71972-4

[27] Kallenbach L., Nelson C. J., \& Coutts J. H. (2002). Yield, quality and persistence of grazing- and hay-type alfalfa under three harvest frequencies. Agronomy Journal, 94, 1094-1103. https://doi.org/10.2134/agronj2002.1094

[28] Rimi F., Macolino S., Leinauer B., Lauriault L. M., \& Ziliotto U. (2014): Fall dormancy and harvest stage impact on alfalfa persistence in a subtropical climate. Agronomy Journal, 106(4), 1258-1266. https://doi.org/10.2134/agronj13.0495

[29] Karamanos, A. J., Papastylianou, P. T., Stavrou, J., \& Avgoulas, C. (2009). Effects of water shortage and air temperature on seed yield and seed performance of alfalfa (Medicago sativa L.) in a Mediterranean environment. Journal of Agronomy and Crop Science, 190, 408-419. https://doi.org/10.1111/j.1439-037X.2009.00380.x

[30] Vasileva, V. \& Kostov, O. (2015). Effect of mineral and organic fertilization on alfalfa forage and soil fertility. Emirates Journal of Food and Agriculture, 27, 678-686. https://doi.org/10.9755/ejfa.2015.05.288

[31] Stanisavljević, R., Beković, D., Đukić, D., Stevović, V., Terzić, D., Milenković, J., \& Đokić, D. (2012). Influence of plant density on yield components, yield and quality of seed and forage yields of alfalfa varieties. Romanian Agriculture Research, 29, 245-254.

[32] Milovanovic, B., Ducić, V., Radovanovic, M., \& Milivojević, M. (2017). Climate regionalization of Serbia according to Köppen climate classification. Journal of the Geographical Institute "Jovan Cvijic" SASA, 67, 103-114. https://doi.org/10.2298/IJGI1702103M

[33] Štrbanović, R., Stanisavljević, R., Đukanović, L., Poštić, D., Marković, J., Gavrilović, V., \& Dolovac, N. (2017). Variability and correlation of yield and forage quality in alfalfa varieties of different origin. Journal of Agricultural Science, 23(1), 128-137.

\section{Contact information:}

Rade STANISAVLJEVIĆ, PhD, Principal Research Fellow

Institute for Plant Protection and Environment,

Teodora Drajzera 9, 11040, Belgrade, Serbia

E-mail: stanisavljevicrade@gmail.com

Aleksandar VUKOVIĆ, PhD, Assistant professor

University of Priština, Faculty of Agriculture,

Kopaonička bb., 38228 Lešak

E-mail: vukovicc64@g mail.com 
Dragan V. PETROVIĆ, PhD, Full professor

University of Belgrade, Faculty of Agriculture,

Nemanjina 6, 11081 Belgrade - Zemun, Serbia

E-mail: epetrodr@agrif.bg.ac.rs

Rade L. RADOJEVIĆ, PhD, Full professor

University of Belgrade, Faculty of Agriculture,

Nemanjina 6, 11081 Belgrade - Zemun, Serbia

E-mail: rrade@agrif.bg.ac.rs

Saša BARAĆ, PhD, Full professor

University of Priština, Faculty of Agriculture,

Kopaonička b.b., 38228 Lešak

E-mail: sasabarac1@gmail.com

Zoran I. MILEUSNIĆ, PhD, Associate professor

University of Belgrade, Faculty of Agriculture

Nemanjina 6, 11081 Belgrade - Zemun, Serbia

E-mail: zoranm@agrif.bg.ac.rs

Vjekoslav TADIĆ, PhD, Associate professor

(Corresponding author)

University of J. J. Strossmayer in Osijek,

Faculty of Agrobiotehnical Sciences Osijek,

Vladimira Preloga 1, 31000 Osijek, Croatia

E-mail: vtadic@fazos.hr 